\title{
Disrupting Homophily Through SmallWorld
}

Elliott Brannon, MPH ${ }^{1,2}$; Robert Cesaro ${ }^{1}$; Whit Froehlich ${ }^{1}$

\section{ABSTRACT}

\section{Purpose}

SmallWorld strengthens communities by facilitating high-quality connections among community members. ${ }^{1}$ When communities form, community members tend to connect most easily with those with whom they share similarities such as interest, race, and gender. In sociology, this is called homophily and leads to silos and unhealthy communities. ${ }^{2}$ SmallWorld disrupts homophily by making random connections within communities.

Research suggests that connected communities are happier, more inclusive, more innovative, and more productive. ${ }^{3,4,5}$

\section{Product}

SmallWorld's flexible and easy-touse software changes community networks by connecting members who would have otherwise not met. Once community members sign up, our automated system sends out random pairings at regular intervals (every week, 2 weeks, etc.). After being paired, community

\section{Company Purpose}

Communities often feel divided and disconnected because members contact each other and set up a meeting over lunch, coffee, or another low-commitment, one-on-one interaction. These connections allow community members to develop deeper relationships throughout their community. SmallWorld can be used for communities that are just forming, communities that have existed for years, or even events such as conferences.

\section{Next Steps}

Given the positive feedback received so far within the University of Michigan Medical School community, SmallWorld pilots are planned across a strategically selected array of communities: academic communities, health care communities, faith communities, conferences, and businesses. We plan to offer pilot sites our services for 6 months and then focus on analyzing the connection and survey data that we collect. Use of SmallWorld is currently free of charge, but this is expected to change as user numbers increase.

individual members have a natural tendency to connect more easily with other members like 
themselves. ${ }^{1}$ In sociology, this tendency is called homophily, and it leads to the formation of silos within communities. ${ }^{2}$ These silos are often based on similarities such as common interests, race, and gender. Silos contribute to inefficient and ineffective communication within communities, racial and gender discrimination, and isolation, which can ultimately lead to depression in community members. Research suggests that connected communities are happier, more inclusive, more innovative, and more productive. ${ }^{3,4,5}$

Community members who share fewer similarities are less likely to meet. When they do meet however, more information is exchanged because they have different knowledge bases and unique perspectives. ${ }^{6}$ SmallWorld is an app aimed at connecting community members, who may otherwise not have met, in an effort to promote knowledge and idea sharing.

These new connections would allow community members to develop deeper relationships within their community. Every connection that SmallWorld facilitates will not result in a close friendship, but this is not the point: the power of SmallWorld comes from a greater understanding of community members, community resources, and the open culture these connections create.

Many connection apps exist-Tinder, NeverEatAlone, Argo, Tea with Strangers-but SmallWorld is different in one important way: rather than the success of a single connection, the focus is on the health of the community. SmallWorld allows community members to contribute to their community simply by having lunch or coffee with their coworkers, colleagues, or classmates. Most connection apps use algorithms that bring together people who are similar, but this reinforces silos that already exist. By using random connections among community members, SmallWorld strengthens bonds among different community members and facilitates resource sharing within the community.

\section{Product}

SmallWorld's flexible and easy-to-use software improves community networks by connecting members who would have otherwise not met via the process shown in Figure 1.

Community administrators are encouraged to secure community support before using SmallWorld in their community. Participation is

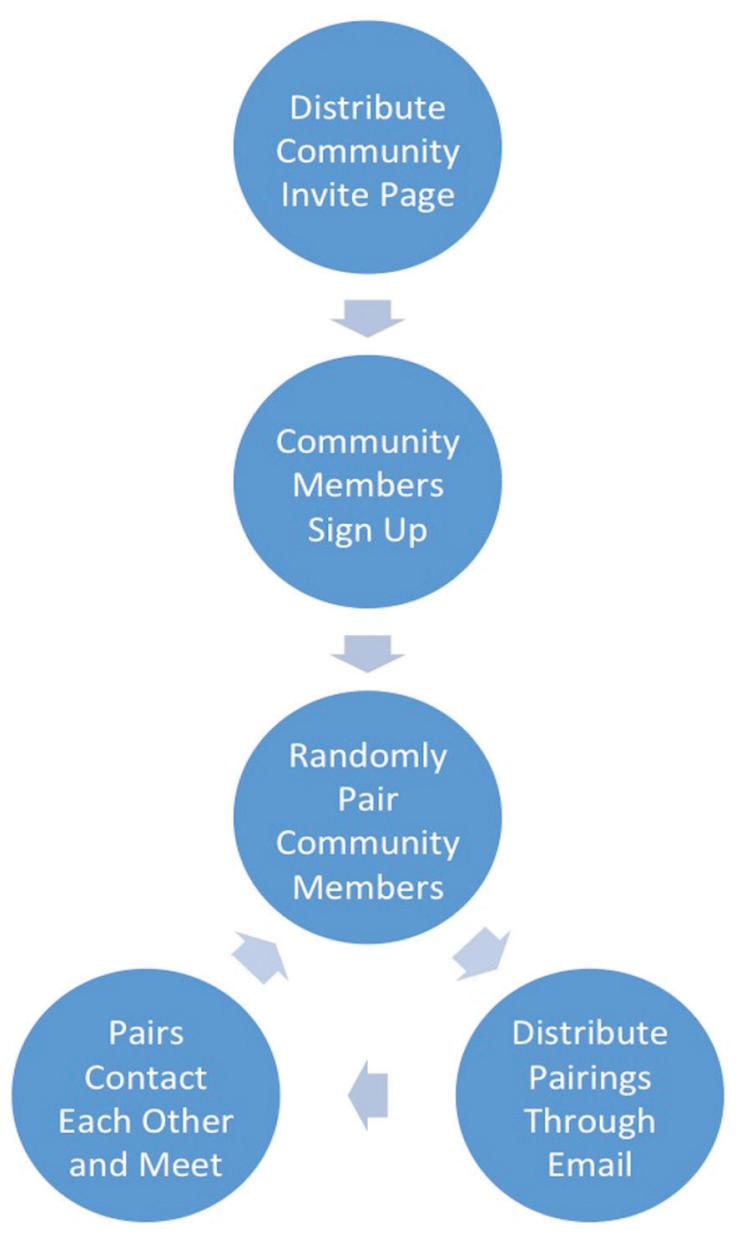

FIGURE 1. Flowchart describing the process behind the SmallWorld app. First, a community administrator creates a personalized invite page and sends this page to community members. Next, members use the page to learn about SmallWorld and sign up with their name and e-mail address. SmallWorld then randomly pairs community members. These pairings are distributed through e-mail. After being paired, community members contact each other and set up a meeting over lunch, coffee, or another one-on-one interaction. These steps are repeated at a regular interval determined by the community: weekly, monthly, or any other frequency. 
completely voluntary. Community administrators may eventually consider incentives such as paying for coffee to increase participation.

\section{Preliminary User Feedback}

SmallWorld's first pilot was in the University of Michigan Medical School during the 2015-2016 academic year. SmallWorld distributed more than 600 connections, and 109 first year medical students participated. A survey was sent to the participating students, of which 34\% responded. Of these respondents, 100\% reported that they found value in the connections they made through SmallWorld. Students reported that SmallWorld connected them with classmates they would have otherwise not met:

I've met with several people I hadn't yet talked to or connected with. This has given me a great opportunity to get to know more of my classmates, especially ones who are in a different social circle. I've really enjoyed [SmallWorld]!

I got to connect with fellow classmates and learn more about them in a more organic way than a traditional orientation-esque ice breaker. I also was able to exchange advice about school, research, and extracurricular activities.

I've been able to chat at length with classmates instead of just in passing. Also, I've been paired with some great people that otherwise I wouldn't have socialized with. It's been a great experience!

SmallWorld's initial target populations are academic communities, but the service has the potential to benefit a wide array of groups: health care communities, faith communities, organizations, and conferences. The meetings we facilitate may result in a close friendship, work collaboration, or innovative research. SmallWorld will also facilitate many connections, however, that do not have such a large impact. This does not mean that such connections are not important; the summation of these microimpacts may be greater than the most visible collaborations or friendships that result from SmallWorld connections. We hope that by facilitating a greater understanding of their community for community members, we will help reduce discrimination within communities.

\section{Business Model}

SmallWorld's business model will be a subscriptionbased service charged to community administrators. Premium subscriptions will offer additional features such as workplace well-being metrics so that community administrators can understand the impact SmallWorld is having on their community.

SmallWorld is focused on strengthening communities, and this is explicitly stated in our mission. We are a social enterprise with a triple bottom line of people, planet, and profits. SmallWorld is a workerowned cooperative, and SmallWorld software will be open source. The high growth and technological nature of our work has led us to conclude that a sustainable for-profit structure fits our requirements better than a nonprofit structure. Because SmallWorld is worker-owned, we will not accept traditional venture capital investments, but we will accept redeemable preference shares, since this type of investment does not dilute governance rights. Similar to Loomio, a company devoted to democratic ideals, we feel "revenue is not an end in itself, but a means towards achieving a core social purpose."

\section{Future Directions}

As of November 2016, we have set up pilot sites in classes, in health clinics, in dorms, among faculty, and in faith communities throughout the University of Michigan and the city of Ann Arbor. In each community, SmallWorld will operate independently; that is, community members will only be paired with other members from the same community. We plan to work with the UM Office of Diversity, 
Equity, and Inclusion to identify UM communities that would benefit from using SmallWorld. In an academic setting, communities can range in size from a classroom to the entire campus, and each site must carefully consider their intentions for using SmallWorld and expected engagement from community members.

Within the next 2 years, we hope to spread to at least 10 additional academic centers across the United States. In health care communities, we will bring together everyone from physicians to front desk staff. This will lead to conversations across the health care continuum and may lead to the identification of systems issues that would not have otherwise been addressed.

\section{Acknowledgments}

SmallWorld has received funding from JumpStart Grants at the Center for Entrepreneurship and TechArb, the UM Student Venture Accelerator.

\section{References}

1. Stephens JP, Heaphy E, and Dutton J. High quality connections. In: Cameron K, and Spreitzer G eds. Handbook of Positive Organizational Scholarship. New York: Oxford University Press, 2011: 385-399.

2. Cacioppo JT, et al. Happiness and the invisible threads of social connection. In: Eid M, Larsen R, eds. The Science of Subjective Well-Being. New York: Guilford, 2008:195-219.

3. McPherson M, Smith-Lovin L, and Cook JM. Birds of a feather: homophily in social networks. Ann Rev Socio. 2001;27:415-444.

4. Lovejoy WS, and Sinha A. Efficient structures for innovative social networks. Management Science. 2010;56(7):1127-1145.

5. Ellison SF, Mullin WP. Diversity, social goods provision, and performance in the firm. J Econ Manag Strategy. 2014;23(2):465-481.

6. Granovetter M. The strength of weak ties. Am J Soc. 78(6):1360-1380.

7. Loomio, About Us. 2016. Retrieved from https:// www.loomio.org/about. 